\title{
Informal Supporters of Elder Abuse Victims: Who Are They and What Is Their Experience Seeking Help?
}

\author{
Silvia Fraga Dominguez ${ }^{1,2}$ (D) Jennifer E. Storey ${ }^{3} \cdot$ Emily Glorney $^{2}$
}

Accepted: 29 November 2021 / Published online: 13 December 2021

(c) The Author(s) 2021

\begin{abstract}
This study examined the characteristics and experiences of informal supporters of elder abuse victims, including family members, friends, and neighbors-referred to as concerned persons. The researchers utilized secondary data from a UK national elder abuse helpline to investigate the profile and help-seeking experiences (including the impact of helping) of concerned persons reporting abuse to the helpline. The researchers focused on one year of data (2017-2018), and 1623 records met inclusion criteria. Of these, 1352 were reported by a concerned person, and descriptive statistics are provided to describe this sample. The help-seeking experience was investigated using qualitative content analysis. Concerned persons were primarily female family members, often adult children of the victim and siblings of the perpetrator. They faced barriers to helping the victim, particularly in relation to formal services. Many also reported impact as a result of knowing about the abuse or helping the victim; particularly to their mental health and their relationship with the victim. Findings indicate that concerned persons often face substantial barriers and negative impact when they support elder abuse victims. There is a need to advance research on concerned persons and identify ways of effectively supporting them, given their essential role in facilitating elder abuse victims' access to formal services.
\end{abstract}

Keywords Elder mistreatment $\cdot$ Concerned persons $\cdot$ Family members $\cdot$ Help-seeking $\cdot$ Barriers

Elder abuse (EA) (also known as elder mistreatment or older adult abuse or mistreatment) is defined as "a single or repeated act or lack of appropriate action, occurring within a relationship of trust, which causes harm or distress to an older person" (World Health Organization [WHO], 2021, para. 2). There are different types of EA: financial abuse or exploitation, physical, psychological or sexual abuse, and neglect (Yon et al., 2017). Although EA can be perpetrated by non-family members, such as professionals or friends, EA is often family-perpetrated (Dow et al., 2020). EA is a

Silvia Fraga Dominguez

Silvia.FragaDominguez@gcu.ac.uk

Jennifer E. Storey

J.storey@kent.ac.uk

Emily Glorney

Emily.Glorney@rhul.ac.uk

1 Department of Psychology, Glasgow Caledonian University, Glasgow G4 0BA, UK

2 Royal Holloway, University of London, Egham TW20 0EX, UK

3 University of Kent, Canterbury CT2 7NR, UK common problem worldwide, with recent systematic reviews finding a pooled prevalence rate in the community of $15.7 \%$ (Yon et al., 2017) and 64\% of staff admitting to engaging in mistreatment in institutions such as care homes (Yon et al., 2018). In the United Kingdom (UK), EA is estimated to affect between $2.6 \%$ and $4 \%$ of adults 66 and older living in private households (O'Keeffe et al., 2007). Although this statistic is lower than worldwide estimates, this difference could be due to the use of stricter definitions in the specific study. In addition, there are no more recent prevalence studies in the UK, so prevalence could be higher. EA has been linked to severe consequences for victims such as psychological and physical harm, including higher mortality rates (Yunus et al., 2019).

An important challenge in the field is under-reporting (Fraga Dominguez et al., 2021a), with only between 4 and $14 \%$ of cases estimated to reach the attention of formal services (Acierno et al., 2020; Amstadter et al., 2011; Lachs \& Berman, 2011). Under-reporting leads to victims and perpetrators not receiving help, which may result in escalation (Burnes et al., 2019a; Storey \& Perka, 2018), risk to other potential victims, and negative consequences for advancing 
research, given that studies will often be based on data for the cases that are reported, providing a biased perspective of the phenomenon (Storey, 2020). Research to combat underreporting has primarily focused on the perspective of professionals (i.e., the challenges they experience with screening, detection, and reporting of EA cases; e.g., Killick \& Taylor, 2009). Practically, tools have been developed to increase recognition of EA signs and EA evaluation, and countries such as the United States, England, Australia, and Canada have developed mandatory reporting policies to increase professional reporting, with varying scopes (Donnelly, 2019; Lachs \& Pillemer, 2015). Less frequently, research on underreporting has focused on the victims' perspectives of helpseeking and the barriers they face (see Fraga Dominguez et al., 2021a for a review). The latter has often highlighted the existence of unique barriers for EA that is perpetrated by family members, particularly adult children (Dow et al., 2020; Fraga Dominguez et al., 2021a).

An area that has received more limited attention is the perspective of informal supporters of EA victims. In other fields of interpersonal violence, victims frequently disclose their victimization to informal sources (e.g., friends or family), who are often the first disclosure recipients (Voth Schrag et al., 2021). Thus, informal receivers of interpersonal violence victims' disclosures are usually in a privileged position to both support victims and seek help on their behalf. In fact, intimate partner violence researchers have identified research with this group as essential in advancing intervention programming (Sylaska \& Edwards, 2014). Importantly, the involvement of these informal supporters in EA cases has been found to predict victims' formal service utilization, thus stressing their important role in connecting EA victims with help (Burnes et al., 2019b). In addition, the concerned person's role may be particularly important when EA victims have cognitive problems that make it harder for these victims to recognize the abuse and access services (Fraga Dominguez et al., 2020, 2021a; Liu et al., 2021).

Several EA researchers have focused on the perspective of non-abusing family members, friends, and neighbors who support EA victims. Breckman et al. (2017) named these informal supporters "concerned persons" (p. 719), and we adopt the term in this paper. Much of the available research related to concerned persons has focused on the likelihood of a third party recognizing a situation as EA or deciding to become involved (e.g., Aday et al., 2017; Hourglass, 2020). Less commonly, researchers have focused on these third parties' help-seeking experience, such as its impact or potential challenges accessing support (Breckman et al., 2017; Kilaberia \& Stum, 2020). Breckman et al.'s survey study (2017) focused on the experiences and behavior of people who had encountered EA. They found that, of those who knew someone experiencing mistreatment, $60 \%$ became involved as helpers, thus indicating that, despite the potential barriers, such as fear of retaliation (Storey \& Perka, 2018), a substantial number of non-professional third parties would become involved in an EA situation. Their study also highlighted the possibility of negative consequences for those who are aware of the abuse, and even more so for those who sought help, given that they found helping status to be positively associated with level of distress (Breckman et al., 2017). The level of distress attributed to the abusive situation was also predicted by the concerned person being female, having lower income, or increased age.

Overall, research about concerned persons' profile, help-seeking role and experience, as well as the impact that these activities have on them remains limited, and has primarily been conducted in the United States. The limited research on non-professional supporters indicates that concerned persons may have an important impact on victims' engagement with services (Burnes et al., 2019b). It also suggests that those who get involved in helping an older victim of abuse may experience distress as a result (Breckman et al., 2017). Little is known about the barriers they face when seeking help, and other aspects of helpseeking (e.g., facilitators, sources of help; Fraga Dominguez et al., 2021a). Due to the important role that concerned persons have in supporting older victims of abuse, there is a need to develop a further understanding of their experiences to inform service provision and understand how to best support this population.

\section{The Present Study}

This study sought to improve the understanding of concerned persons' roles and experiences in a UK context. The study focused on concerned persons' characteristics, experience of help-seeking, and the impact suffered due to their knowledge of and involvement in EA cases. The aim was to answer the following research questions:

1) What is the profile of concerned persons (gender, relationship with victim and perpetrator)?

2) What are concerned persons' help-seeking experiences, in relation to the following areas? a. Barriers to helpseeking; b. Facilitators to help-seeking; c. Sources of help; d. Responses from sources of help and degree of success in improving the victims' situation

3) What do concerned persons want to achieve by seeking help (i.e., contacting a helpline) and what are their longterm wishes in terms of third-party intervention?

4) What is the impact on the concerned person of knowing about the abuse and/or getting involved in helping the victim? 


\section{Design and Methodology}

\section{Research Design and Data Source}

This study involved a secondary analysis of cross-sectional data and is part of a larger study focused on help-seeking in EA. The data encompassed all the records entered in an EA helpline's dataset between 22/5/2017 and 22/5/2018. The data source was Hourglass' free helpline. Hourglass, formerly called Action on Elder Abuse and founded in 1993, is the only EA-dedicated charity in the UK (Hourglass, n.d.; O'Keefe et al., 2007; Podnieks et al., 2010). Recently, the organization has broadened their focus to include the general promotion of safer aging (Hourglass, n.d.). Hourglass' helpline operates from Monday to Friday during working hours and has been operational since 1998 (Action on Elder Abuse, 2008), with cases recorded and managed electronically since 2017 . The main purpose of the helpline is to offer advice to older adults affected by abuse by a trusted person, as well as other individuals concerned about the abuse of an older adult. Making an enquiry will not prompt an investigation or a formal report, and enquirers may remain anonymous. Nonetheless, staff and volunteers may recommend contacting adult safeguarding or the police and may, in some cases, make a referral to adult safeguarding if this is requested by the enquirer.

When the helpline receives an enquiry, the operator records a free text describing the enquirer's situation, the help needed, and the advice provided. The charity gathers the data for their own records, and as such there are limitations to the analysis of data not gathered primarily for research purposes (e.g., missing data, inconsistent records). In addition, because the helpline is a source of advice, enquirers might contact the helpline when they have not yet found a solution for a case of abuse, thus the researchers expected the sample to be biased towards more negative experiences. However, the sample is also likely to reflect cases where enquirers are in the process of seeking help or considering help-seeking, and as such is unique in offering insight about these experiences.

For clarity of reference in this paper, those alleged to have engaged in EA will be referred to as perpetrators and those who were subjected to abuse will be referred to as victims.

\section{Procedure}

The first author received access to the helpline records through a written agreement and signed a confidentiality agreement with the charity. The researchers received ethical approval from their university.
The focus of the study were all enquiries (i.e., calls, emails, and letters) during the period from May 2017 to May $2018(N=2538)$. Data coding started in October 2018 and was completed in May 2019. Prior to coding the data, the researchers developed inclusion criteria. For inclusion in this study as a report by a concerned person, the case had to:

1) Be considered EA, as understood by the charity Hourglass and the WHO (2021). To guide decision-making in unclear cases, attention was paid to the helpline's recommended actions (e.g., whether they recommended an EA organization or otherwise indicated that the case did not constitute EA). This procedure is consistent with a recent study focused on helpline enquiries (Weissberger et al., 2020).

2) Contain information about:

i. Several key variables: a) abuse type(s), b) victim's gender, c) victim-perpetrator relationship, and d) enquirer's identity (victim vs non-victim).

ii. Help-seeking from the perspective of the victims and non-victim enquirers, including concerned persons.

\section{Materials}

A data collection tool was developed to gather the data needed for the purposes of this study. The first author focused on the free texts and used the data collection tool to gather case characteristics. This tool was created based on previous literature, particularly a systematic review of victims' helpseeking behavior (Fraga Dominguez et al., 2021a). The coding scheme recorded primarily nominal variables, some with categories (e.g., concerned person's relationship with the victim), but many coded dichotomously as present or absent (e.g., barriers related to formal services). It also recorded variables as free texts, to be analyzed using qualitative content analysis. The variables recorded and relevant to the present study are included in Table 1 . For reference, other variables relating to general sample characteristics are as follows: a) Victim and Perpetrator Characteristics: Demographic characteristics (e.g., gender, age). b) Victim and Perpetrator Relationship: Family member (including type), friend, acquaintance, professional. c) Abuse Characteristics: Abuse type(s) (financial, physical, psychological, neglect, sexual), abuse location (e.g., victim's home, care or nursing home, sheltered housing, hospital, other).

\section{Final Sample}

After applying inclusion criteria, out of the 2538 entries in the system, 1623 (64\%) met inclusion criteria. The main reason for excluding 915 cases was that they did not meet the EA definition $(n=207,23 \%)$ or that there was not enough 
Table 1 Data collection variables relevant to the concerned persons in the study

\begin{tabular}{|c|c|c|}
\hline \multirow[t]{2}{*}{ Section } & \multicolumn{2}{|l|}{ Variables } \\
\hline & With Pre-Identified Categories & $\begin{array}{l}\text { With Free Texts Analyzed Using Qualitative Content } \\
\text { Analysis }\end{array}$ \\
\hline Enquirer Characteristics & $\begin{array}{l}\text { - Enquirer type: victim vs non-victim. } \\
\text { - Non-victim: relationship with the victim, relationship } \\
\text { with the perpetrator. }\end{array}$ & \\
\hline $\begin{array}{l}\text { Concerned Persons' } \\
\text { Help-Seeking Behav- } \\
\text { ior }\end{array}$ & $\begin{array}{l}\text { - Previous help-seeking behavior: yes/no. } \\
\text { - Source(s) of help-seeking. Persons, professionals, or } \\
\text { services that a person seeks help from, categorized as: } \\
\text { 1. Informal: family, friends, acquaintances. } \\
\text { 2. Formal: social services, police, charities, etc. } \\
\text { - Responses from sources. The immediate response } \\
\text { obtained from sources of help after help-seeking, } \\
\text { verbally or non-verbally, as well as the helpfulness of } \\
\text { the response: categorized as positive, negative, mixed, } \\
\text { neutral. } \\
\text { - Outcomes of help-seeking. The success in stopping or } \\
\text { improving the abusive situation, categorized as: } \\
\text { 1. The abuse ceased; 2) The situation improved but the } \\
\text { abuse did not cease; 3) The situation worsened; 4) No } \\
\text { change. } \\
\text { - Prior confrontation of the perpetrator (yes/no). } \\
\text { - Helpline outcomes: immediate outcomes of contact- } \\
\text { ing the helpline, understood as the advice offered to } \\
\text { enquirers. Categorized as the type of service advised: a) } \\
\text { Social services, including adult safeguarding (similar to } \\
\text { Adult Protective Services); b) Police; c) Legal services; } \\
\text { d) Care Quality Commission; e) Management; f) Other } \\
\text { (see Note). }\end{array}$ & $\begin{array}{l}\text { - Facilitators to current (i.e., to the helpline) and/or } \\
\text { previous help-seeking behavior. Understood as anything } \\
\text { (e.g., a circumstance, a feeling, or a belief) that makes it } \\
\text { easier for a person to seek help. } \\
\text { - Barriers to current (i.e., to the helpline) and or/previous } \\
\text { help-seeking behavior. Understood as anything (e.g., a } \\
\text { circumstance, a feeling, or a belief) that makes it harder } \\
\text { for a person to seek help. Classified in the themes iden- } \\
\text { tified for EA victims in Fraga Dominguez et al. (2021a) } \\
\text { with content analyzed qualitatively: } \\
\text { 1) Fear of consequences; 2) Individual feelings or } \\
\text { circumstances; 3) Formal services; 4) Family barriers; } \\
\text { 5) Social network; 6) Perception of abuse; 7) Cultural, } \\
\text { generational, o religious. } \\
\text { - Perpetrator's responses to confrontation. } \\
\text { - Impact of abuse and/or seeking help. } \\
\text { - Anticipated outcomes from helpline contact: enquirer's } \\
\text { goals in contacting the helpline (i.e., help needed). } \\
\text { - Wishes towards third-party intervention: understood } \\
\text { broadly as the wishes towards help obtained from third } \\
\text { parties in relation to the abusive situation. }\end{array}$ \\
\hline
\end{tabular}

Care Quality Commission: monitors care quality in care homes and other care services. Management: contacting management at a care home or nursing home. Other: contacting Hourglass again, a variety of organizations relating to health concerns (e.g., dementia) or abuse/crime (e.g., Action Fraud UK)

information to conclude whether the case was EA $(n=192$, $21 \%)$. A small number of enquiries excluded $(n=30,3 \%)$ were repeat enquiries (flagged as such by the helpline staff) occurring within the period examined. Information for those matched enquiries was merged; thus, the 1623 cases represent unique cases. For the present study, only cases reported by a concerned person (family member, friend, neighbor, or acquaintance) were included. Within the original 1623 cases, $189(12 \%)$ were reported by victims, $67(4 \%)$ by professionals, $3(0.2 \%)$ by the perpetrator, and in 12 cases $(0.7 \%)$ the relationship with the victim was unknown. Thus, those cases were excluded, and the final sample for the present study was 1352 cases.

\section{Inter-Rater Reliability}

To ensure the coding was performed reliably, a research assistant (RA) independently coded 254 cases ( $10 \%$ of the original sample of records; $N=2538$ ). The RA signed a confidentiality agreement with the charity before receiving a sample of 254 fully anonymized cases from the first author, randomly generated from the original sample. The first author trained the RA on the data collection tool and several practice cases were coded together to ensure consistency. The RA started coding in February 2019 and completed it in July 2019.

Inter-rater reliability was calculated for these cases using Cohen's Kappa for categorical variables and Intraclass Correlation Coefficient (two-way, mixed methods, absolute agreement) for continuous variables (e.g., age). Cohen's Kappa results ranged from .68 to .87 , indicating good to very good agreement (Altman, 1999), and $\mathrm{ICC}_{1}$ ranged from .80 to 1 , indicating good to excellent agreement (Koo \& Li, 2016). See Table 2 for the average inter-rater reliability results by category.

\section{Data Analysis}

Data were entered into IBM SPSS Statistics (Version 21), which was used to generate descriptive statistics for the variables with pre-identified categories. For variables that were gathered using free texts, data were analyzed qualitatively with the support of QSR NVivo (Versions 11 and 12). Qualitative content analysis was used, which has been 
Table 2 Inter-rater reliability average results by category

\begin{tabular}{llll}
\hline Section & Kappa & $\mathrm{ICC}_{1}$ & $\begin{array}{l}\text { Percent } \\
\text { agree- } \\
\text { ment }\end{array}$ \\
\hline Case and enquirer characteristics & .82 & .99 & \\
Victim characteristics & .82 & 1 & 100 \\
Perpetrator characteristics & .87 & .99 & 99.8 \\
Victim-perpetrator relationship character- & .70 & & \\
$\quad$ istics & & & \\
Abuse characteristics & .74 & .80 & 98.3 \\
Previous help-seeking and facilitators & .68 & & 100 \\
Barriers & .74 & & 99.6 \\
Advice & .78 & & \\
\hline
\end{tabular}

Percent agreement was calculated when Cohen's Kappa could not be calculated because the variable was a constant

deemed appropriate for summarizing large datasets and to generate categories of content (Drisko \& Maschi, 2016). In this study, the researcher used a combination of deductive and inductive approaches. This combination was appropriate for the type of data in this study, where for many variables, pre-identified categories (i.e., derived from research, such as barrier themes) existed and were deductively generated. However, within these categories, the content was inductively analyzed.

For these analyses, the researcher became familiar with the data by reading it carefully before assigning codes. Subsequently, the researcher identified common themes and created subthemes. These themes and subthemes were revised iteratively as needed, and the approach to coding was datadriven. The researcher used memos to document and review decisions (i.e., to merge codes or create overarching themes), which were also used to reflect on the researcher's impressions of the data and the analytic process, which facilitated reflexivity throughout (Shenton, 2004). The codes were primarily descriptive, which minimizes bias. To illustrate themes and subthemes, examples are provided; however, to preserve anonymity, quotes are not included. Given the large sample size, and to illustrate how many cases referred to specific themes or subthemes, frequencies are reported (Drisko \& Maschi, 2016).

\section{Results}

\section{General Sample Characteristics}

For context here, basic sample characteristics are presented. In-depth details about the sample are presented in Fraga Dominguez et al. (2021b). Within the subsample of 1352 cases reported by concerned persons, the victims were primarily female $(n=882,65 \%)$, and the abuse suffered predominantly financial $(n=859,64 \%)$ and psychological $(n=623,46 \%)$. The abuse happened at home in most cases ( $n=984,79 \%$; 105 cases missing) and was frequently perpetrated by family members $(n=988,73 \%)$, usually adult children $(n=658,49 \%)$.

\section{Profile of Concerned Persons}

Most concerned persons were female $(n=968,74 \% ; 28$ cases missing). As shown in Table 3, concerned persons were primarily family members of the victim and among those, most were the victims' adult children. They were also commonly related to the perpetrator, primarily the perpetrators' siblings.

\section{Help-Seeking Experience}

The majority of cases had information about at least one of the variables of interest in relation to help-seeking experience, with only 14 cases (1\%) lacking information for all the variables being examined.

\section{Barriers to Help-Seeking}

In 595 cases (44\%) a barrier was identified in EA reporting by concerned persons. Due to the lack of research on concerned persons specifically, the themes for victims identified in a previous systematic review (Fraga Dominguez et al., 2021a) were used as a framework for coding, with content analyzed within those themes. However, 193 cases (32\%) related to new themes. The most commonly mentioned barriers related to formal services, followed by fears and barriers related to the social network. The most common subthemes of each of those barrier themes and examples of these can be found in Table 4. In terms of the new barrier themes, these commonly related to the perpetrator's behavior or influence on the victim, followed by the victim's behavior.

\section{Facilitators to Help-Seeking}

In 542 cases (40\%), there were facilitators and/or circumstances that prompted the concerned person to seek help. Most commonly, concerned persons were seeking help due to specific circumstances or triggers, such as recently becoming aware of, or learning new information about, abuse ( $n=216,40 \%)$; a concern for the victim's wellbeing/ safety $(n=75,14 \%)$; or an escalation of abuse $(n=72,13 \%)$. The most common facilitators were having proof of abuse $(n=27,5 \%)$ or knowledge about EA or where to seek help $(n=10,2 \%)$. 
Table 3 Relationship of the concerned person with the victim and the perpetrator

\begin{tabular}{|c|c|c|}
\hline & \multicolumn{2}{|c|}{ Cases } \\
\hline & $n$ & $\%$ \\
\hline \multicolumn{3}{|l|}{ Relationship with the victim ${ }^{a}$} \\
\hline Family member & 1077 & 79.7 \\
\hline Adult child & 632 & 46.7 \\
\hline Grandchild & 119 & 8.8 \\
\hline Child in-law & 98 & 7.2 \\
\hline Niece/nephew & 77 & 5.7 \\
\hline Sibling & 34 & 2.5 \\
\hline Partner & 14 & 1.0 \\
\hline Parent & 1 & 0.1 \\
\hline Other family member & 93 & 6.9 \\
\hline Family member unspecified & 9 & 0.7 \\
\hline Friend & 93 & 6.9 \\
\hline Neighbor & 81 & 6.0 \\
\hline Acquaintance & 78 & 5.8 \\
\hline Other & 23 & 1.7 \\
\hline \multicolumn{3}{|l|}{ Relationship with the perpetrator ${ }^{b}$} \\
\hline Family member & 791 & 58.7 \\
\hline Sibling & 351 & 26.0 \\
\hline Niece/nephew & 76 & 5.6 \\
\hline Sibling in-law & 72 & 5.3 \\
\hline Adult child & 48 & 3.6 \\
\hline Stepchild & 39 & 2.9 \\
\hline Aunt/uncle & 37 & 2.7 \\
\hline Cousin & 36 & 2.7 \\
\hline Child in-law & 17 & 1.3 \\
\hline Grandchild & 4 & 0.3 \\
\hline Parent & 4 & 0.3 \\
\hline Partner & 2 & 0.2 \\
\hline Other family member & 88 & 6.5 \\
\hline Family member unspecified & 17 & 1.3 \\
\hline Acquaintance & 283 & 21.0 \\
\hline $\begin{array}{l}\text { Professional (e.g., carer, health care } \\
\text { or legal professional) }\end{array}$ & 143 & 10.6 \\
\hline Stranger & 74 & 5.5 \\
\hline Neighbor & 47 & 3.5 \\
\hline Friend & 5 & 0.4 \\
\hline Other & 5 & 0.4 \\
\hline
\end{tabular}

${ }^{\mathrm{a}} n=1352$

${ }^{\mathrm{b}} n=1348$

\section{Sources of Help}

Out of the 1352 concerned persons, 460 (34\%) reported seeking help previously, most $(n=435,95 \%)$ by contacting a formal source of help. Some had contacted an informal source $(n=13,3 \%)$, and some both $(n=10,2 \% ; 2$ cases unknown). The most common specific sources contacted were social services or adult safeguarding $(n=180,40 \%)$, the police $(n=112,25 \%)$, or legal advice (e.g., a solicitor; $n=49,11 \%$ ); however, a wide range of services were contacted.

\section{Responses from Sources of Help and Outcomes}

Where the type of response was known ( $n=371,81 \% ; 89$ cases unknown), the responses were coded as predominantly negative $(n=170,46 \%)$, followed by neutral $(n=96,26 \%)$, positive $(n=57,15 \%)$, and mixed (both positive and negative; $n=48,13 \%)$. At the time of the enquiry, where outcome was known ( $n=370,80 \%$; 90 cases unknown), most concerned persons had been unsuccessful in stopping or improving the abuse situation $(n=314,85 \%)$. In some cases, the situation had improved $(n=42,11 \%)$, while in a few cases it had worsened following seeking help $(n=8,2 \%)$. In a minority of cases, the enquirers had been successful in resolving the abusive situation ( $n=6,2 \%)$.

\section{Perpetrator Confrontation and Responses}

In 80 cases (6\%), the concerned person had confronted the perpetrator. Perpetrators' responses to confrontation were gathered and analyzed using qualitative content analysis. Of the 80 , six (8\%) responses were unknown or unclear. After reading the content of the other responses, the researcher classified the type of responses by whether the confrontation was successful in improving the situation of abuse. The most common outcome was that the confrontation was unsuccessful, but there were no changes in the abuse (i.e., it did not worsen; $n=51,69 \%$ ). For example, the perpetrator refused to talk or meet with the concerned person or lied about the abuse. In 18 cases (24\%) the confrontation was not successful, and it resulted in further abuse or other negative consequences. For example, the perpetrator made allegations against the concerned person or their relatives (to services or to the victim) or became abusive verbally or physically towards them. In a minority of cases $(n=9$, $12 \%$ ) there had been a change in the situation, but it had not resolved yet (e.g., the perpetrator had acknowledged their wrong and might be trying to seek help or return money). Only in one case (1\%) the confrontation was successful (i.e., the abuse stopped).

\section{Anticipated Outcomes from Helpline Contact and General Attitudes Towards Third-Party Intervention}

Information about concerned persons' goals when contacting the helpline (e.g., what they wanted to achieve) was available in 334 cases (25\%) and was analyzed using qualitative content analysis. The main goals of enquirers when 
Table 4 Concerned persons' barriers by theme

\begin{tabular}{|c|c|c|c|c|}
\hline \multirow[t]{2}{*}{ Barrier themes } & \multirow[t]{2}{*}{ Most common barrier subthemes } & \multirow[t]{2}{*}{ Examples } & \multicolumn{2}{|c|}{ Cases } \\
\hline & & & $n$ & $\%$ \\
\hline \multirow[t]{6}{*}{ Formal services } & & & 399 & 67.1 \\
\hline & Response from services overall or unspecified. & Inadequate response, retaliation, services cannot help & 123 & 20.7 \\
\hline & Response from specific services. & $\begin{array}{l}\text { Social services, police, legal services, residential facilities } \\
\text { (inadequate response, unable to help, retaliation) }\end{array}$ & 118 & 19.8 \\
\hline & Victims' attitudes or blocking of services. & Victim will not support the CP's engagement with services & 14 & 2.4 \\
\hline & CP's lack of knowledge of where to seek help. & & 12 & 2.0 \\
\hline & Perpetrator's blocking or interference. & $\begin{array}{l}\text { Perpetrator rejects carers' or other formal services' help } \\
\text { offered to the victim }\end{array}$ & 9 & 1.5 \\
\hline \multirow[t]{6}{*}{ Fears } & & & 42 & 7.1 \\
\hline & Fear for themselves. & Fear of perpetrator's or others' repercussions & 28 & 4.7 \\
\hline & Fear for the victim. & $\begin{array}{l}\text { Fear of victims' wellbeing impacted (e.g., becoming dis- } \\
\text { traught, leaving their house and going into a care home, } \\
\text { getting in danger or in trouble) }\end{array}$ & 11 & 1.8 \\
\hline & Fear for their relationship with the victim. & $\begin{array}{l}\text { Fear of a breakdown of the relationship or not being able to } \\
\text { visit the victim }\end{array}$ & 4 & 0.7 \\
\hline & Fear for their family. & Fear of causing problems to the CP's family & 3 & 0.5 \\
\hline & Fear for the perpetrator. & $\begin{array}{l}\text { Being wrongfully accused, becoming homeless or losing their } \\
\text { job }\end{array}$ & 3 & 0.5 \\
\hline \multirow[t]{4}{*}{ Social network } & & & 27 & 4.5 \\
\hline & Lack of support from social network. & Other family members are unsupportive or cannot help & 7 & 1.2 \\
\hline & CP's estrangement from social network. & $\mathrm{CP}$ is estranged from other family or people who could help & 6 & 1.0 \\
\hline & Active blocking from social network. & Blocking services or not allowing the $\mathrm{CP}$ to see victim & 5 & 0.8 \\
\hline Individual feelings & & $\begin{array}{l}\text { Mental health problems that make it harder to seek help, } \\
\text { ambivalence, helplessness }\end{array}$ & 12 & 2.0 \\
\hline Family & & $\begin{array}{l}\text { Wanting to avoid family conflicts or affect the victim's rela- } \\
\text { tionship with a family perpetrator }\end{array}$ & 6 & 1.0 \\
\hline Perception of abuse & & $\begin{array}{l}\text { Lacking information about the abuse or not perceiving it as } \\
\text { serious enough }\end{array}$ & 4 & 0.6 \\
\hline \multirow[t]{3}{*}{ New themes } & & & 193 & 32.4 \\
\hline & The perpetrator's behavior. & $\begin{array}{l}\text { The perpetrator's interference or their influence on or manipu- } \\
\text { lation of the victim }\end{array}$ & 45 & 7.6 \\
\hline & The victim's behavior. & Unwillingness to talk about the situation or in denial about it & 28 & 4.7 \\
\hline
\end{tabular}

Barriers were not exclusive, so the sum of percentages exceeds 100. $C P=$ concerned person. Not all barrier themes have subthemes or examples The percentages are calculated with respect to the cases where there were barriers reported $(n=595)$

contacting the helpline can be found in Table 5. Primarily, concerned persons wanted general advice or advice regarding a specific service/measure that they were considering. In addition, they frequently wanted more information about laws, or the legal obligations of services or individuals, older adults' rights, and the nature of EA itself.

In terms of the type of advice provided by the helpline, among the 1352 cases reported by concerned persons, the helpline recorded the recommendations they provided in 1152 (85\%) cases. The most common recommendation was to contact social services $(n=613,53 \%)$, followed by legal services $(n=384,33 \%)$. Other concerned persons were signposted to contact the police ( $n=167,15 \%)$, management $(n=50,4 \%)$ or the Care Quality Commission $(n=28,2 \%)$.
Finally, many were signposted to "other" services $(n=508$, $44 \%)$. See Table 1 for clarification about these categories.

Another study aim was to gather more information about concerned persons' attitudes towards third-party intervention: for example, what they want to happen when others, particularly formal services, get involved in helping the victim or themselves, and what they want to avoid. Both the concerned persons' wishes towards intervention and the outcomes that they wanted to avoid related to several main areas. The most commonly mentioned in both what concerned persons wanted and what they wanted to avoid were specific support from services, victims' housing or living arrangements, and the disclosure of abuse and its outcomes. They also reported their wishes for the perpetrators. The 
Table 5 Concerned persons' goals when enquiring from the helpline

\begin{tabular}{|c|c|c|c|}
\hline \multirow[t]{2}{*}{ Things concerned persons want } & \multicolumn{2}{|c|}{$\begin{array}{l}\text { Fre- } \\
\text { quency }\end{array}$} & \multirow[t]{2}{*}{ Examples } \\
\hline & $n$ & $\%$ & \\
\hline General advice & 128 & 38.3 & $\begin{array}{l}\text { - For example, about how to help or support the victim, investigate } \\
\text { abuse, or about taking "the right direction". }\end{array}$ \\
\hline Advice about a specific service or measure & 87 & 26.0 & $\begin{array}{l}\text { - Particularly, regarding legal advice and intervention, or involving } \\
\text { police or adult safeguarding. }\end{array}$ \\
\hline General or specific information & 38 & 11.4 & $\begin{array}{l}\text { - Particularly, about laws, services' obligations, older people's rights, } \\
\text { and information about EA. }\end{array}$ \\
\hline Report or inform about abuse & 25 & 7.5 & $\begin{array}{l}\text { - For example, they wanted to report the abuse, inform the charity about } \\
\text { abuse, their enquiry to be recorded, or to be part of a case study. They } \\
\text { also wanted assistance in reporting (e.g., how to report and to whom). }\end{array}$ \\
\hline Advice on next steps & 21 & 6.3 & $\begin{array}{l}\text { - Wanting to know how to proceed following lack of success from the } \\
\text { services contacted or steps taken to date. }\end{array}$ \\
\hline Hourglass to intervene & 17 & 5.1 & $\begin{array}{l}\text { - The charity to intervene, investigate, or to contact other services on } \\
\text { their behalf (e.g., raise a safeguarding alert). }\end{array}$ \\
\hline Talk about the situation with someone or discuss concerns & 13 & 3.9 & - Wanting to talk to someone outside of their informal support network. \\
\hline Reassurance about next steps & 11 & 3.5 & $\begin{array}{l}\text { - CPs wanted advice about whether the service or measure they were } \\
\text { considering was the right choice. }\end{array}$ \\
\hline Advice on dealing with services and professionals & 10 & 3.0 & $\begin{array}{l}\text { - For example, how to proceed during an upcoming meeting or how to } \\
\text { talk to professionals. }\end{array}$ \\
\hline Reassurance and confirmation & 4 & 1.2 & $\begin{array}{l}\text { - CPs wanted to know whether their concerns were justified and whether } \\
\text { they were acting correctly. }\end{array}$ \\
\hline
\end{tabular}

$n=334$. The total percentage exceeds 100 because a number of CPs provided several goals for the enquiry. $C P=$ concerned person

most common categories within each of these areas can be found in Table 6.

\section{Impact}

Data about impact on the concerned person of the abuse and help-seeking experience was recorded in over a third of cases $(n=586,43 \%)$. All the data gathered were analyzed using qualitative content analysis. Informed by prior literature (Breckman et al., 2017), the researcher aimed to create codes within two different areas: type of impact previously experienced and the reason for the impact reported (whether it was due to helping the victim, due to knowing about or being impacted by the abuse, or both). After the researcher became familiar with the data for impact on the concerned person, and noticing that in some cases there were additional people (not specific to the direct victim) affected by the abuse, the researcher decided to classify each case by whether any person additional to the concerned person and victim had been impacted.

\section{Type of Impact}

The impact of the abuse or seeking help on behalf of the victim can be found in Table 7 . The most common type of impact was psychological or mental health impact, followed by a negative impact on the relationship with the victim (e.g., not being able to see the victim).

\section{Reason for the Impact Reported}

In most cases, the reason for the reported impact was knowing about the abuse or being impacted by the abuse situation itself ( $n=445,76 \%$ ). However, in several cases, from the recorded data, it was a result of helping or trying to help with the abusive situation $(n=77,13 \%)$. In some cases, there was impact related to both the abusive situation and trying to help ( $n=56,10 \%)$, and in several cases the reason for the impact was unclear $(n=8,1 \%)$.

\section{Target of the Impact}

Although in most cases the enquirer was the only person impacted $(n=546,93 \%)$, there were 21 cases where one other person was impacted. This was most commonly the enquirer's partner/spouse $(n=8)$ or the enquirer's sibling $(n=7)$, followed by their child $(n=3)$, mother $(n=2)$, or friend $(n=1)$. In a similar number of cases $(n=16)$, there were two or more persons impacted in addition to the enquirer, usually the "family" ( $n=13)$, but also identified as siblings $(n=2)$, and a husband and a daughter $(n=1)$. There were two cases in which the impact was specified as affecting only someone other than the enquirer-their spouse. 
Table 6 Concerned persons' wishes towards third-party intervention

\begin{tabular}{|c|c|c|c|c|c|}
\hline Area of Focus & $n$ & $\%$ & Most Common Categories & $n$ & $\%$ \\
\hline \multicolumn{6}{|l|}{ Things CPs Want $(n=168)$} \\
\hline \multirow[t]{6}{*}{ Specific support } & \multirow[t]{6}{*}{122} & \multirow[t]{6}{*}{72.6} & - Legal advice or measures & 23 & 13.7 \\
\hline & & & - Social services' or adult safeguarding's involvement & 16 & 9.5 \\
\hline & & & • Police involvement & 12 & 7.1 \\
\hline & & & - Investigation into the matter & 12 & 7.1 \\
\hline & & & $\begin{array}{l}\text { - Complaining to services or getting services to acknowledge errors and } \\
\text { act on abuse }\end{array}$ & 8 & 4.8 \\
\hline & & & - Informal help (e.g., collaborating with other CPs) & 7 & 4.2 \\
\hline \multirow[t]{4}{*}{ Victims' housing or living arrangements } & \multirow[t]{4}{*}{22} & \multirow[t]{4}{*}{13.1} & - Victim being placed in residential care & 7 & 4.2 \\
\hline & & & - The perpetrator to move out & 5 & 3.0 \\
\hline & & & - The victim to remain at home or return home & 5 & 3.0 \\
\hline & & & - The victim to move out of the place where abuse is occurring & 2 & 1.2 \\
\hline \multirow[t]{3}{*}{ Disclosure and outcomes of disclosure } & \multirow[t]{3}{*}{17} & \multirow[t]{3}{*}{10.1} & - Remaining anonymous or confidential & 4 & 2.4 \\
\hline & & & $\begin{array}{l}\text { - Talking to the media about their story, publicizing experience, or } \\
\text { being part of a case study }\end{array}$ & 4 & 2.4 \\
\hline & & & - Obtaining others' reassurance & 2 & 1.2 \\
\hline \multirow[t]{3}{*}{ The perpetrator } & \multirow[t]{3}{*}{10} & \multirow[t]{3}{*}{6.0} & - Legal consequences or prosecution & 3 & 1.8 \\
\hline & & & • To "pay" or be "named and shamed" & 3 & 1.8 \\
\hline & & & - Help or treatment & 2 & 1.2 \\
\hline Relationship or interaction with the perpetrator & 6 & 3.6 & $\begin{array}{l}\text { - Talking to the perpetrator, confronting them, or trying to solve situa- } \\
\text { tion together }\end{array}$ & & \\
\hline The victim & 3 & 1.8 & - The victim to be looked after and safe & & \\
\hline Relationship with the victim & 2 & 1.2 & - Being able to see the victim & & \\
\hline \multicolumn{6}{|l|}{ Things CPs do not Want $(n=70)$} \\
\hline \multirow[t]{3}{*}{ Specific support from services } & \multirow[t]{3}{*}{34} & \multirow[t]{3}{*}{48.6} & - Social services' involvement & 7 & 10.0 \\
\hline & & & - Police involvement & 6 & 8.6 \\
\hline & & & $\begin{array}{l}\text { - Services not investigating the allegations, not keeping CPs informed, } \\
\text { or "sweeping things under the carpet" }\end{array}$ & 5 & 7.1 \\
\hline Disclosure and outcomes of disclosure & 25 & 35.7 & $\begin{array}{l}\text { - Negative consequences of reporting such as making matters worse, } \\
\text { causing the victim distress, or having services alert the perpetrators. }\end{array}$ & & \\
\hline \multirow[t]{4}{*}{ Victims' housing or living arrangements } & \multirow[t]{4}{*}{6} & \multirow[t]{4}{*}{8.6} & - The victim being placed in residential care & 2 & 2.9 \\
\hline & & & - The victim going home to abusive situation & 2 & 2.9 \\
\hline & & & - The victim leaving their home & 1 & 1.4 \\
\hline & & & - The victim being separated from another victim & 1 & 1.4 \\
\hline The victim & 5 & 7.1 & - Upsetting or stressing the victim & & \\
\hline \multirow[t]{2}{*}{ The perpetrator } & \multirow[t]{2}{*}{3} & \multirow[t]{2}{*}{4.3} & - Getting the perpetrator in trouble & 2 & 2.9 \\
\hline & & & - The perpetrator "getting away" with abuse & 1 & 1.4 \\
\hline Relationship with the victim & 3 & 4.3 & $\begin{array}{l}\text { - Worsening their relationship with the victim or not being able to see } \\
\text { the victim }\end{array}$ & & \\
\hline
\end{tabular}

$C P=$ concerned person. The total percentage exceeds 100 because categories were not exclusive

\section{Discussion}

The purpose of the present study was to explore the profile of concerned persons, their experience and wishes in seeking help for the victim, and the impact on them of the abusive situation and the help-seeking process. Concerned persons were primarily female family members, often helping a parent who was being abused by another family member, very frequently the concerned person's sibling. The concerned persons' experience of seeking help was overall negative, and barriers to helpseeking primarily related to formal services. They also experienced barriers related to the perpetrator's behavior and challenges when the victim did not agree with seeking action. Finally, the impact on concerned persons was varied and wide-ranging in severity, affecting their mental and physical health, financial status, and relationship with the victim. 
Table 7 Impact suffered by concerned persons by type

\begin{tabular}{|c|c|c|c|}
\hline Impact type & $n$ & $\%$ & Common examples \\
\hline $\begin{array}{l}\text { Psychological impact or an } \\
\text { impact on the CP's mental } \\
\text { health }\end{array}$ & 498 & 85.0 & $\begin{array}{l}\text { - Concern, anxiety-related symptoms (i.e., fear, alertness). } \\
\text { - Mood-related symptoms (e.g., depression or depressive symptoms). } \\
\text { - Self-blame or guilt. } \\
\text { - Difficulties coping. } \\
\text { - Trauma-related symptoms. }\end{array}$ \\
\hline Relationship with the victim & 82 & 14.0 & $\begin{array}{l}\text { - Not allowed to see the victim or talk to the victim. } \\
\text { - Difficulties seeing the victim, talking to them, or doing so privately. } \\
\text { - The victim had "shut them out", was angry at them, or there was a breakdown in the relationship. }\end{array}$ \\
\hline Burden of seeking help & 47 & 8.0 & $\begin{array}{l}\text { - This included seeking help for a long time, sometimes many years, many contacts with services, } \\
\text { and many different actions to try to seek remedy for the situation, as well as dealing with negative } \\
\text { experiences with and inadequate responses from services. }\end{array}$ \\
\hline $\begin{array}{l}\text { Subject to abuse or threats, } \\
\text { primarily by the perpetrator }\end{array}$ & 30 & 5.2 & $\begin{array}{l}\text { - This involved being on the receiving end of threats, aggressive, and rude behavior, shouting or } \\
\text { screaming, hostility, and being asked for money. In one extreme case, the CP was threatened with } \\
\text { homicide by the perpetrator. }\end{array}$ \\
\hline Subject to false allegations & 20 & 3.4 & $\begin{array}{l}\text { - CPs had been subject to false allegations, such as safeguarding alerts, harassment allegations, or } \\
\text { been accused of being the ones abusing the victim. In some cases, this had led to "trouble" with } \\
\text { the police or to an investigation by safeguarding professionals. }\end{array}$ \\
\hline Financial impact & 19 & 3.2 & $\begin{array}{l}\text { - Spending money to support the victim, such as being asked by the victim for money, to provide } \\
\text { things for the victim, helping to buy food or clothes, or paying the victim's care home fees. } \\
\text { - Money spent on solicitors and legal advice, ranging from } 1000 \text { to } 80,000 \text { pounds. }\end{array}$ \\
\hline Physical health impact & 8 & 1.4 & $\begin{array}{l}\text { - Attacked or assaulted by the perpetrator. } \\
\text { - Attacked by the victim. } \\
\text { - Physical deterioration. }\end{array}$ \\
\hline Other impact & 76 & 13.0 & $\begin{array}{l}\text { - Feeling ignored, not listened to, or helped by services. } \\
\text { - Lacking information about the victim. } \\
\text { - Impact on the CP's family or family relationships. }\end{array}$ \\
\hline
\end{tabular}

$n=586 . C P=$ concerned person

\section{Concerned Persons' Profile}

The familial relationship between concerned persons and alleged perpetrators is likely to create many challenges in seeking help, but also for professionals interacting with family members when there is suspected abuse. The finding that concerned persons are primarily children of victims reporting abuse perpetrated by a sibling adds to the literature on EA dynamics. Even though family members are often the most common perpetrators of EA (Dow et al., 2020; Weissberger et al., 2020), they are also the most common advocates for the victim. Given that most enquiries to the helpline over a year were made by concerned person, the requirement for sensitive management of and response to EA concerns is emphasized.

\section{Barriers and Facilitators to Help-Seeking}

The present study has expanded knowledge on barriers and facilitators to seeking help in EA, by focusing on concerned persons' perspectives and experiences. Barriers most commonly related to formal services, likely due to the context of the helpline. Given that the helpline is primarily a source of advice, often including the recommendation to contact other services (Action on Elder Abuse, 2008), helpline staff are likely to explore enquirers' previous attempts to seek help, in order to know where to signpost enquirers. Barriers related to fear (e.g., of repercussions) were also common, consistent with previous research where third parties involved in EA cases were afraid of retaliation for reporting the abuse (Storey \& Perka, 2018). These worries do not seem to be unwarranted, as some concerned persons in the study had experienced retaliation from services or individual perpetrators. Barriers related to the social network were also common, and several concerned persons did not have the support of other relatives or friends, which may have prompted feelings of responsibility over the abuse (Moschella et al., 2018).

Barriers related to services and a new theme of barriers related to the victim's behavior not only highlight the perspective of concerned persons, but, at the same time, offer an insight into the struggles of services to respond to EA and address third-party concerns. Safeguarding generally requires the victim's consent when the victim has mental capacity, prior to assessment and intervention (Department of Health and Social Care, 2020). However, the victim's view may differ with the views of concerned persons, who may be particularly reluctant to intervene when other family members are involved (Dow et al., 2020), all of which might mean professionals are unable to assess the allegations. Professionals need to be mindful that concerned persons, even 
if informed of legislation, will still struggle with seeing a loved one being hurt.

In terms of triggers and facilitators leading to help-seeking, concerned persons sought help out of concern for the victim's safety and also following an escalation of abuse. This is consistent with previous findings for EA victims (Fraga Dominguez et al., 2021a) and may be related to feelings of responsibility over the victim's wellbeing (Moschella et al., 2018). It is important to understand ways of supporting concerned persons to make earlier disclosures, to avoid further harm. Nonetheless, it is possible that, by waiting to report, concerned persons are merely respecting the victims' wishes not to involve services.

\section{Sources and Goals of Help-Seeking and Responses from Sources of Help}

In terms of concerned persons' help-seeking patterns, they had primarily sought help from formal services, generally receiving negative responses and achieving little success in stopping the abuse. There could be an overestimation of negative experiences with services, given that those enquirers with less success are probably more likely to contact the helpline. However, these experiences are still important in shaping practice and understanding how services can provide a better response. The number of concerned person enquirers is relatively high $(n=1352)$ and only covers one year of data from the helpline, suggesting there are many family members, friends, neighbors, and acquaintances who may be struggling to support EA victims and interact with services. Concerned persons also confronted the perpetrator, and almost a quarter were met with negative consequences for themselves or the victim, such as increased abuse. The findings suggest that confrontation is rarely successful and may put concerned persons and victims at risk of further harm. Thus, it is not an advisable or safe way of resolving abuse. However, confronting the perpetrator may be something that concerned persons prefer if they want to privately address a family matter, or where the victim does not support formal intervention (Dow et al., 2020; Mackay, 2017). For this reason, in order to reduce risk, confrontation needs to be explored and discussed actively by professionals when they interact with concerned persons. Professionals need to make concerned persons aware of the risks of confrontation for victims and concerned persons, and evaluate safer alternatives, which may require formal services' involvement. Breckman et al. (2017) recommended that services for concerned persons should include education about EA and ways of being effectively involved without harm to themselves.

At the moment of enquiring from the helpline, most concerned persons wanted general advice about how to proceed, or specific advice in their interaction with services. This is consistent with the purpose of the charity's helpline.
However, some needed general knowledge about EA, relevant legislation, and the rights of older people. These findings suggest there is still a need for more population awareness about EA and related laws and policies (Breckman et al., 2017; Fraga Dominguez et al., 2021a; Mackay, 2017). Long-term, concerned persons expressed wishes in several areas (specific help, the victim's housing and living arrangements, and the outcomes of disclosure), indicating that there is a need to explore these varied wishes in their interaction with services. Nonetheless, because of the use of secondary data, only a small number of cases had data available regarding wishes, and thus future studies should gather primary data to investigate concerned persons' goals and needs.

\section{Impact of Abuse and Help-Seeking on Concerned Persons}

The current study findings expand previous research by identifying some of the ways in which concerned persons are impacted (Breckman et al., 2017; Kilaberia \& Stum, 2020). The impact of abuse and help-seeking on concerned persons ranged widely in severity, but it was clear that, for some, it was not mere concern that they were experiencing, but more severe impact to their mental health, as well as victimization by the perpetrator. Abuse by the perpetrator was sometimes severe, including a threat of homicide, physical assault, and false allegations. These findings can be considered in light of recent suggestions that concerned persons may need to be framed as secondary victims (Kilaberia \& Stum, 2020). Another major impact of the abuse for the concerned person was the loss of their ability to see the victim, due to the perpetrator's control or restrictions placed by them. This impact is likely to cause particular anguish in concerned persons, who were frequently family members supporting a parent and blocked by a sibling from seeing the victim. In addition to what the concerned persons described to the helpline, their involvement in supporting the victim probably did not stop there. Many concerned persons were advised by the helpline on how to proceed further or on new routes to explore, such as contacting adult safeguarding or legal services.

Previous research found that helping an EA victim was associated with more distress than only knowing about the abuse (Breckman et al., 2017). In the present study, in most cases it was not possible to determine that the impact on the concerned person was a result of seeking help on behalf of the victim rather than the result of knowing about the abuse itself and the perpetrator's abusive behaviors. However, given that many concerned persons reported seeking help before, it is likely that some of the described impact was associated with seeking help. Therefore, there might have been an underestimation of the impact that was caused by seeking help and not simply by the abuse or knowledge 
about the abuse. Nevertheless, these two types of impact, from knowledge about the abuse itself and seeking help, may sometimes be intertwined. For example, a perpetrator who may be isolating the victim from a family member may increase their isolation once they notice that the family member is aware of the abuse and trying to seek help. In this example, the concerned person would be affected both by the abuse itself and by the consequences of trying to support the older adult.

Notably, in some cases, the concerned person making the enquiry was not the only one impacted, and another third party (usually another family member) was also suffering from a similar impact as a result of the abuse and/or supporting the victim. This highlights the reach of EA, which we know severely affects victims (Yunus et al., 2019) and emphasizes the need to support concerned persons. Because the current study used secondary data, gathered at a particular point in time, it is possible that many more enquirers and other third parties experienced impact that they simply did not report or that was not recorded, so there could be an under-estimation of the impact experienced. Importantly, there are ways of supporting this group of people, some of which are already being implemented. For example, the New York City Elder Abuse Center (NYC EAC) launched a helpline specifically targeted at concerned persons (Elman et al., 2020; NYC EAC, 2018), considering their specific needs and how they may be impacted by the experience of witnessing abuse or supporting an older adult who is abused (Breckman et al., 2017). It may also be necessary to involve concerned persons in intervention planning (Sylaska \& Edwards, 2014) and explore how they are perceived by services.

\section{Implications for Practice and Policy}

Practitioners - particularly from social services, police, and legal advice - should be mindful when interacting with a victim's family members and friends. Concerns by family members - the majority of concerned persons - should be taken seriously; however, given that the perpetrator is likely to be a family member as well, this can be confusing for practitioners. In fact, they may have difficulties establishing who is trying to help and who is harming the victim. In those cases, interviewing the victim alone will be paramount, and so will be seeking corroborating evidence from multiple sources and services. Such a protocol will ensure that victims and concerned persons are protected from the perpetrator. Importantly, the fact that EA perpetrators, victims, and reporters may all be related, stresses the importance of considering family dynamics by policy makers (Dow et al., 2020).

Concerned persons need support, and the negative response they receive from services can make them feel despondent and hopeless. Specific helplines for them, or helplines and services that understand their unique experiences and needs, are necessary (Elman et al., 2020). Professionals should not ignore those concerned persons and should remain in touch and listen carefully to their concerns. If concerned persons are supported in remaining close to victims, they might be able to notice when the situation escalates or when there is an emergency and services must intervene (Mackay, 2017). They may also be the first ones to know when victims reach a threshold and decide that they support intervention. The New York City Elder Abuse Center's (NYC EAC) helpline for concerned persons (Elman et al., 2020; NYC EAC, 2018) can be used as an example of supporting this population, and future research on service efficacy should be considered when modelling initiatives. Although a specific helpline may not always be appropriate or cost-effective, the experience of the helpline can be used in order to inform the work of existing EA helplines and services that will often be interacting with concerned persons. Finally, further education for concerned persons may be helpful, so that they are aware of relevant legislation and are able to understand how to best manage these cases. For example, focusing on the risk of confrontation, and also emphasizing the need to respect victims' wishes and the legislation around mental capacity and intervention by services (Mackay, 2017).

\section{Limitations}

This study is limited in several ways, primarily because it represents a biased sample of EA cases. First, there is likely a bias towards those experiencing more negative responses in their interaction with services because those may be more likely to continue seeking redress and more willing to enquire from a helpline. However, as highlighted earlier in the discussion, even without knowing the representativeness of these experiences with respect to concerned persons in the general population, the experiences reported in this sample should not be ignored. Importantly, the characteristics of the sample in terms of EA types and victim-perpetrator relationship were consistent with previous research (Joosten et al., 2020; Weissberger et al., 2020).

Second, there are limitations relating to the diversity of the sample in the study. There was no information for the enquirers relating to important areas such as race/ethnicity, socioeconomic backgrounds, and sexual or gender minorities, meaning that it is not possible to understand how representative the sample is of the diversity of the UK population. Recording these characteristics in future samples, with a consideration of intersectionality, will be essential in understanding the different barriers to service access that may be faced by different groups in the population. 
Third, the source of data (e.g., the organization) may affect the data obtained, in that Hourglass' campaigning work and organizational characteristics may attract specific enquiries. Nevertheless, this helpline was chosen due to its strengths (i.e., representativeness, national recognition, and special focus on EA; Podnieks et al., 2010). Finally, the EA cases are not substantiated and are based on self-reporting by helpline enquirers at a particular point in time. Nevertheless, because the aim of the study was to understand enquirers' perspectives of seeking help, their perceptions are of utmost importance.

\section{Conclusions}

The present study aimed to explore the profile of family members, friends, neighbors, and acquaintances of EA victims ("concerned persons"), their help-seeking experience, and the impact of knowing about abuse and/or seeking help on behalf of the victim. Concerned persons were primarily the victims' female family members, who experienced many barriers at different levels, but particularly in relation to formal services. Seeking help on behalf of the victim came at a great cost, particularly psychologically. The study provides support for the need to continue investigating the experience of concerned persons. Additionally, it suggests that practitioners may need to provide tailored support to these concerned persons, given that they are in an ideal position to assist victims, and connect victims with formal services, but may not be able to do so without appropriate assistance.

Acknowledgments The authors would like to thank the charity Hourglass for their support with this project, by allowing access to their records. The views presented in this paper represent those of the authors. The authors would also like to thank Anjali Wisnarama for her help during data collection by undertaking secondary coding of the data.

Funding The first author was supported by a college studentship awarded by Royal Holloway, University of London.

\section{Declarations}

Conflict of Interest We have no conflict of interest to declare.

Ethical Approval Ethical approval received by Royal Holloway, University of London on 7th May 2018 (ID 994-2018-07-05-12-13).

Open Access This article is licensed under a Creative Commons Attribution 4.0 International License, which permits use, sharing, adaptation, distribution and reproduction in any medium or format, as long as you give appropriate credit to the original author(s) and the source, provide a link to the Creative Commons licence, and indicate if changes were made. The images or other third party material in this article are included in the article's Creative Commons licence, unless indicated otherwise in a credit line to the material. If material is not included in the article's Creative Commons licence and your intended use is not permitted by statutory regulation or exceeds the permitted use, you will need to obtain permission directly from the copyright holder. To view a copy of this licence, visit http://creativecommons.org/licenses/by/4.0/.

\section{References}

Acierno, R., Steedley, M., Hernandez-Tejada, M. A., Frook, G., Watkins, J., \& Muzzy, W. (2020). Relevance of perpetrator identity to reporting elder financial and emotional mistreatment. Journal of Applied Gerontology, 39(2), 221-225. https://doi.org/10.1177/ 0733464818771208

Action on Elder Abuse. (2008). A profile of action on elder abuse. The Journal of Adult Protection, 10(3), 35-38. https://doi.org/10.1108/ 14668203200800018

Aday, R. H., Wallace, J. B., \& Scott, S. J. (2017). Generational differences in knowledge, recognition, and perceptions of elder abuse reporting. Educational Gerontology, 43(11), 568-581. https:// doi.org/10.1080/03601277.2017.1376382

Altman, D. G. (1999). Practical statistics for medical research. Chapman \& Hall/CRC Press.

Amstadter, A. B., Cisler, J. M., McCauley, J. L., Hernandez, M. A., Muzzy, W., \& Acierno, R. (2011). Do incident and perpetrator characteristics of elder mistreatment differ by gender of the victim? Results from the National Elder Mistreatment Study. Journal of Elder Abuse \& Neglect, 23(1), 43-57. https://doi. org/10.1080/08946566.2011.534707

Breckman, R., Burnes, D., Ross, S., Marshall, P. C., Suitor, J. J., Lachs, M. S., \& Pillemer, K. (2017). When helping hurts: Nonabusing family, friends, and neighbors in the lives of elder mistreatment victims. The Gerontologist, 58(4), 719-723. https:// doi.org/10.1093/geront/gnw257

Burnes, D., Acierno, R., \& Hernandez-Tejada, M. (2019a). Helpseeking among victims of elder abuse: Findings from the National Elder Mistreatment Study. The Journals of Gerontology: Series B, 74(5), 891-896. https://doi.org/10.1093/geronb/ gby 122

Burnes, D., Breckman, R., Henderson Jr., C. R., Lachs, M. S., \& Pillemer, K. (2019b). Utilization of formal support services for elder abuse: Do informal supporters make a difference? The Gerontologist, 59(4), 619-624. https://doi.org/10.1093/geront/gny074

Department of Health and Social Care. (2020). Care and support statutory guidance: Safeguarding. Retrieved March 28, 2021, fromhttps://www.gov.uk/government/publications/care-act-statutoryguidance/care-and-support-statutory-guidance\#safeguarding-1

Donnelly, S. (2019). Mandatory reporting and adult safeguarding: A rapid realist review. The Journal of Adult Protection, 21(5), 241-251. https://doi.org/10.1108/JAP-03-2019-0011

Dow, B., Gahan, L., Gaffy, E., Joosten, M., Vrantsidis, F., \& Jarred, M. (2020). Barriers to disclosing elder abuse and taking action in Australia. Journal of Family Violence, 35(8), 853-861. https:// doi.org/10.1007/s 10896-019-00084-w

Drisko, J. W., \& Maschi, T. (2016). Content analysis. Oxford University Press.

Elman, A., Breckman, R., Clark, S., Gottesman, E., Rachmuth, L., Reiff, M., Callahan, J., Russell, L. A., Curtis, M., Solomon, J., Lok, D., Sirey, J. A., Lachs, M. S., Czaja, S., Pillemer, K., \& Rosen, T. (2020). Effects of the COVID-19 outbreak on elder mistreatment and response in new York City: Initial lessons. Journal of Applied Gerontology, 39(7), 690-699. https://doi.org/10.1177/ 0733464820924853

Fraga Dominguez, S., Valiquette, J., Storey, J. E., \& Glorney, E. (2020). Elder abuse intervention and detection: Challenges for professionals and strategies for engagement from a Canadian specialist 
service. Journal of Forensic Nursing, 16(4), 199-206. https://doi. org/10.1097/JFN.0000000000000301

Fraga Dominguez, S., Storey, J. E., \& Glorney, E. (2021a). Helpseeking behavior in victims of elder abuse: A systematic review. Trauma, Violence \& Abuse, 22(3), 466-480. https://doi.org/10. $1177 / 1524838019860616$

Fraga Domínguez, S., Storey, J. E., \& Glorney, E. (2021b). Characterizing elder abuse in the UK: A description of cases reported to a national helpline [Manuscript submitted for publication]

Hourglass. (2020). Safe ageing press release. Retrieved March 28, 2021, from https://www.wearehourglass.org/safer-ageing-pressrelease

Hourglass. (n.d.). What we stand for. Retrieved March 28, 2021, from https://wearehourglass.org/node/27

Joosten, M., Gartoulla, P., Feldman, P., Brijnath, B. \& Dow, B. (2020). Seven years of elder abuse data in Victoria. Senior Rights Victoria. Retrieved March 28, 2021, from https://seniorsrights.org. au/wp-content/uploads/2020/08/SRVNARI_7_Years_Report_ online.pdf.

Kilaberia, T., \& Stum, M. (2020). Concerned family members' helpseeking in elder family financial exploitation. Innovation in Aging, 4(1), 629. https://doi.org/10.1093/geroni/igaa057.2147

Killick, C., \& Taylor, B. J. (2009). Professional decision making on elder abuse: Systematic narrative review. Journal of Elder Abuse \& Neglect, 21(3), 211-238. https://doi.org/10.1080/0894656090 2997421

Koo, T. K., \& Li, M. Y. (2016). A guideline of selecting and reporting intraclass correlation coefficients for reliability research. Journal of Chiropractic Medicine, 15(2), 155-163. https://doi.org/10. 1016/j.jcm.2016.02.012

Lachs, M. S., \& Berman, J. (2011). Under the radar: New York state elder abuse prevalence study, self-reported relevance and documented case studies. Lifespan of greater Rochester, Inc., Weill Cornell medical Center of Cornell University, and New York City Department for the aging. Retrieved March 28, 2021, from http:// www.ocfs.state.ny.us/main/reports/Under\%20the\%20Radar\% 2005\%2012\%2011\%20final\%20report.pdf

Lachs, M. S., \& Pillemer, K. A. (2015). Elder abuse. New England Journal of Medicine, 373(20), 1947-1956. https://doi.org/10. 1056/nejmra1404688

Liu, P. J., Wang, A., Schwab-Reese, L. M., \& Stratton, S. K. (2021). Elder mistreatment victims during the COVID-19 pandemic: Administrative data from San Francisco adult protective services. Journal of Family Violence. Advanced online publication. https:// doi.org/10.1007/s10896-021-00305-1

Mackay, K. (2017). Choosing to live with harm? A presentation of two case studies to explore the perspective of those who experienced adult safeguarding interventions. Ethics and Social Welfare, 11(1), 33-46. https://doi.org/10.1080/17496535.2017.1280069

Moschella, E. A., Bennett, S., \& Banyard, V. L. (2018). Beyond the situational model: Bystander action consequences to intervening in situations involving sexual violence. Journal of Interpersonal Violence, 33(20), 3211-3231. https://doi.org/10.1177/08862 60516635319
New York City Elder Abuse Center (NYC EAC). (2018). NYC Elder Abuse Center's Helpline for Concerned Persons. Retrieved March 28, 2021, from https://nyceac.org/wp-content/uploads/2018/11/ Helpline-10.29.18.pdf

O'Keeffe, M., Hills, A., Doyle, M., McCreadie, C., Scholes, S., Constantine, R., Tinker, A., Manthorpe, J., Biggs, S., \& Erens, B. (2007). UK study of abuse and neglect of older people: Prevalence survey report. National Center for Social Research.

Podnieks, E., Penhale, B., Goergen, T., Biggs, S., \& Han, D. (2010). Elder mistreatment: An international narrative. Journal of Elder Abuse \& Neglect, 22(1-2), 131-163. https://doi.org/10.1080/ 08946560903436403

Shenton, A. K. (2004). Strategies for ensuring trustworthiness in qualitative research projects. Education for Information, 22(2), 63-75. https://doi.org/10.3233/EFI-2004-22201

Storey, J. E. (2020). Risk factors for elder abuse and neglect: A review of the literature. Aggression and Violent Behavior, 50, 101339. https://doi.org/10.1016/j.avb.2019.101339

Storey, J. E., \& Perka, M. R. (2018). Reaching out for help: Recommendations for practice based on an in-depth analysis of an elder abuse intervention programme. The British Journal of Social Work, 48(4), 1052-1070. https://doi.org/10.1093/bjsw/bcy039

Sylaska, K. M., \& Edwards, K. M. (2014). Disclosure of intimate partner violence to informal social support network members: A review of the literature. Trauma, Violence \& Abuse, 15(1), 3-21. https://doi.org/10.1177/1524838013496335

Voth Schrag, R. J., Ravi, K., Robinson, S., Schroeder, E., \& PadillaMedina, D. (2021). Experiences with help seeking among nonservice-engaged survivors of IPV: Survivors' recommendations for service providers. Violence Against Women, 27(12-13), 2313 2334. https://doi.org/10.1177/1077801220963861

Weissberger, G. H., Goodman, M. C., Mosqueda, L., Schoen, J., Nguyen, A. L., Wilber, K. H., Gassoumis, Z. D., Nguyen, C. P., \& Han, S. D. (2020). Elder abuse characteristics based on calls to the National Center on elder abuse resource line. Journal of Applied Gerontology, 39(10), 1078-1087. https://doi.org/10.1177/ 0733464819865685

World Health Organization. (2021). Elder Abuse. Retrieved July 12, 2021, from https://www.who.int/en/news-room/fact-sheets/detail/ elder-abuse

Yon, Y., Mikton, C. R., Gassoumis, Z. D., \& Wilber, K. H. (2017). Elder abuse prevalence in community settings: A systematic review and meta-analysis. The Lancet, 5(2), 147-156. https://doi. org/10.1016/S2214-109X(17)30006-2

Yon, Y., Ramiro-Gonzalez, M., Mikton, C. R., Huber, M., \& Sethi, D. (2018). The prevalence of elder abuse in institutional settings: A systematic review and meta-analysis. European Journal of Public Health, 29(1), 58-67. https://doi.org/10.1093/eurpub/cky093

Yunus, R. M., Hairi, N. N., \& Choo, W. Y. (2019). Consequences of elder abuse and neglect: A systematic review of observational studies. Trauma, Violence \& Abuse, 20(2), 197-213. https://doi. org/10.1177/1524838017692798

Publisher's Note Springer Nature remains neutral with regard to jurisdictional claims in published maps and institutional affiliations. 